\title{
An unusual presentation of leprosy: Lepromatous lymphadenitis
}

Leprosy is a nonfatal, chronic inflammatory disease caused by Mycobacterium leprae, whose clinical manifestations are largely confined to the skin, peripheral nervous system, upper respiratory tract, eyes, and testes.

However, here we are reporting a case of leprosy in a 45-year-old male, who presented with bilateral inguinal lymphadenopathy.

Left inguinal lymph node was excised surgically and was transported in $10 \%$ formalin. Sections were stained with Hematoxylin and Eosin and with modified Ziehl-Neelsen (ZN) technique and were examined under light microscope.

Microscopic examination revealed aggregates of foamy histiocytes surrounded by plasma cell infiltrate. Modified ZN stain was performed which showed foamy histiocytes packed with acid-fast lepra bacilli.

This report highlights the importance of systemic involvement in leprosy, especially the unusual presentation with lymphadenopathy. Hence, clinicians practicing in endemic areas should bear this fact in mind.

Key words: Leprosy, lymphadenopathy, mycobacterium leprae

\section{Anadi Roy Chowdhury, Goutam Bandyopadhyay, Palas Bhattacharyya, Soham Chakraborty}

Department of Pathology, RG Kar Medical College, Kolkata, West Bengal, India

Address for the Correspondence:

Dr. Soham Chakraborty, Department of Pathology,

RG Kar Medical College, Kolkata - 700 004, West Bengal,

E-mail: soham85rgkmc@ yahoo.co.in

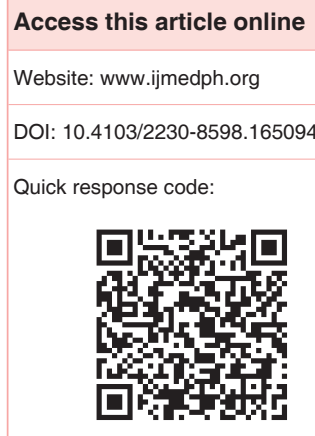

\section{INTRODUCTION}

Leprosy is a nonfatal, chronic inflammatory disease caused by Mycobacterium leprae and presents as a spectrum of clinical manifestations from polar tuberculoid to borderline tuberculoid to mid-borderline to borderline lepromatous to polar lepromatous disease, which is associated with an evolution from asymmetric localized macules and plaques to nodular and indurated symmetric generalized skin manifestations, an increasing bacterial load, and loss of leprae-specific cellular immunity. However, in any part of the spectrum the clinical manifestations are largely confined to the skin, peripheral nervous system, upper respiratory tract, eyes, and testes. ${ }^{[1]}$ The prevalence of leprosy in India is reported to be $0.7 / 10,000$ populations. ${ }^{[2]}$ The disease should be suspected when a patient from an endemic area has suggestive skin lesions or peripheral neuropathy. However, this disease can even present with lymphadenopathy only, as can be seen in this particular case.

\section{CASE REPORT}

A 45-year-old male patient was referred to our institute with the complaints of gradually increasing swelling in the inguinal areas of both sides for 6 months duration. The swellings were painless. On clinical examination, the patient was found to have enlargement of inguinal lymph nodes on both sides, the left-sided swelling was $2.0 \mathrm{~cm}$ and the right sided one was $1.5 \mathrm{~cm}$ in greatest dimension. Excision of the left inguinal lymph node was done surgically and sent to our department for histopathological examination. Fine needle aspiration cytology (FNAC) was not done as it would destroy the lymph nodal architecture.

Left inguinal lymph node was excised surgically and was transported in $10 \%$ formalin. Grossly, the tissue was globular capsulated mass measuring $2.0 \mathrm{~cm} \times 1.8 \mathrm{~cm} \times 1.5 \mathrm{~cm}$. Cut section was homogenous and grayish white in color. Formalin fixed and paraffin embedded sections were made. Sections were stained with Hematoxylin and Eosin stain and also with modified Ziehl-Neelsen (ZN) stain by FiteFaraco's technique, ${ }^{[3]}$ and were examined under light microscope. 
Microscopic examination of the sections showed presence of aggregates of foamy histiocytes surrounded by plasma cell infiltrate replacing normal nodal secondary germinal follicles [Figures 1 and 2]. These foamy histiocytes resembled the lepra cells seen in skin biopsies of patients with lepromatous leprosy. Therefore, a modified ZN stain (with 5\% sulfuric acid decolorization) was performed, which revealed foamy histiocytes packed with acid-fast bacilli (AFB) [Figure 3].

After the diagnosis of lepromatous, leprosy was confirmed in histopathology report, the patient was referred to the dermatology department for further evaluation. On detailed physical examination of the patient, multiple hyperpigmented macules were found on the back and gluteal region, which were dry and ichthyotic with loss of hair. There was a sensory loss to touch and painful stimuli over both the lower extremities. Left common peroneal and posterior tibial nerves were thickened. A skin biopsy was taken which revealed lepromatous leprosy with lepra bacilli in the lepra cells. The patient did not have any documentary evidence of his past medical history. Treatment was started with dapsone, rifampicin, and clofazimine as per multi-drug regime, and he is now on close follow-up.

\section{DISCUSSION}

Leprosy is a chronic granulomatous disease, is one of the major health problems faced by India. It is also endemic in many other countries. Leprosy mainly manifests with cutaneous and neurological involvement, but it also has the propensity to involve lymph node, spleen, bone marrow, eyes, and testes. ${ }^{[4]}$ Incidence of lymph node involvement accompanied by skin lesions with the presence of AFB is $92.2 \% .^{[5]}$

Lymph node involvement in lepromatous leprosy has a very characteristic microscopic appearance. The main change is the progressive accumulation of large, pale, rounded histiocytes ("lepra" or "Virchow" cells), without granuloma formation and with minimal or no necrosis. Wade-Fite and Fite-Faraco stains (modified $\mathrm{ZN}$ reactions) demonstrate packing of the cytoplasm by acid-fast organisms. ${ }^{[6]}$ Although lymph nodes have been reported to be moderately enlarged in leprosy, in the experience of Jopling and McDougall, enlargement is confined to phases of lepra reaction and then there is marked swelling and tenderness, especially of femoral and inguinal groups. ${ }^{[7]}$ As in this case, the morphology is clearly that of lepromatous leprosy.

Kar et al. in their study of 105 leprosy patients found clinical enlargement of lymph nodes in all cases of lepromatous, borderline lepromatous, and borderline types of leprosy. In order of frequency the sites were inguinal (76.2\%), cervical (69.5\%), and axillary $(69.2 \%)$ group of lymph nodes. Nevertheless, it is very unusual to diagnose leprosy primarily by lymph node biopsy. ${ }^{[8]}$

In 2009 Nery et al. showed in their study that multibacillary leprosy, especially close to the lepromatous end of the spectrum, may mimic

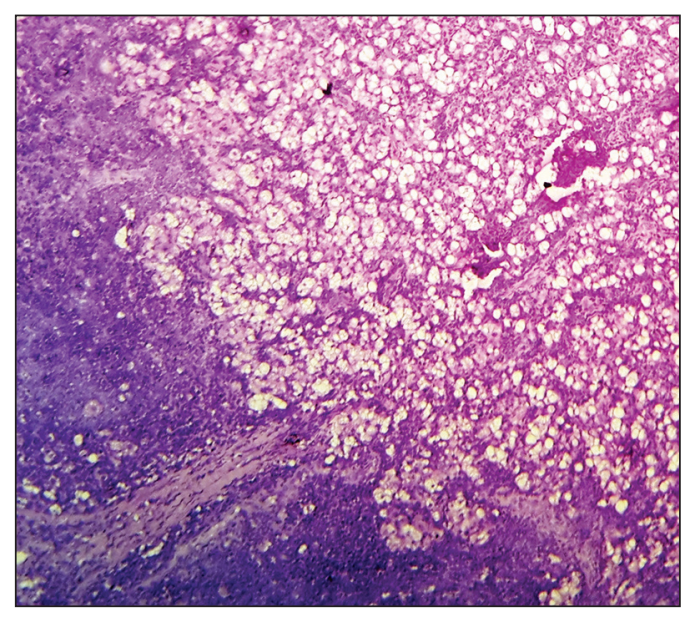

Figure 1: Aggregates of foamy histiocytes surrounded by plasma cell infiltrate replacing normal nodal germinal follicles. $\mathrm{H}$ and $\mathrm{E}$ stain, low power view

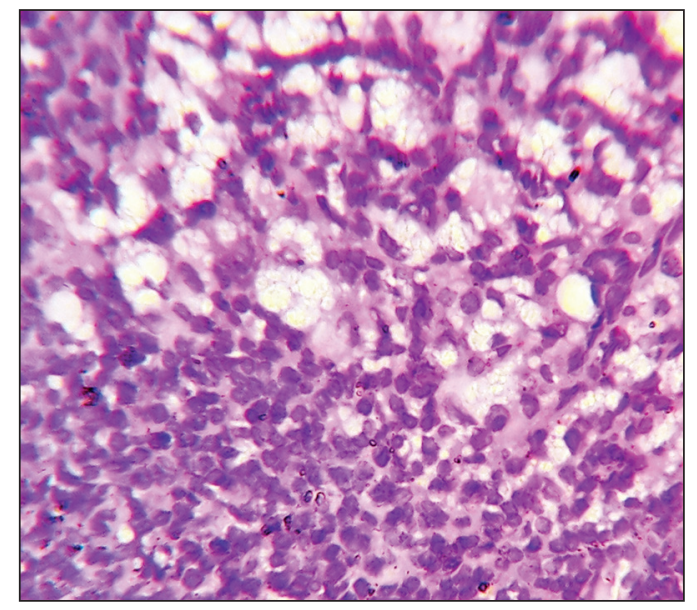

Figure 2: Aggregates of foamy histiocytes surrounded by plasma cell infiltrate replacing normal nodal germinal follicles. $\mathrm{H}$ and $\mathrm{E}$ stain, high power view

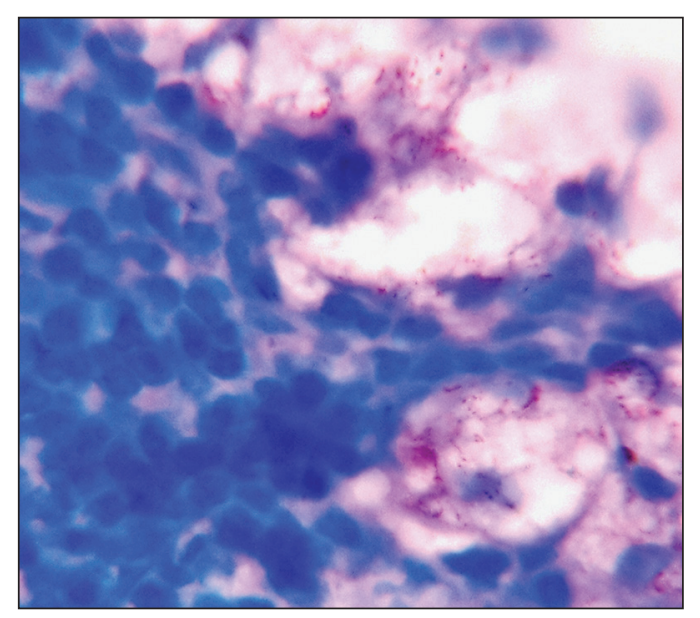

Figure 3: Foamy histiocytes are packed with acid-fast lepra bacilli. Modified Ziehl-Neelsen stain

other diseases, and the patient cannot be diagnosed without a biopsy or a slit skin smear examination. Clinicians working in an endemic 
area do not always include leprosy in their differential diagnosis, especially when the clinical presentation is unusual. However, leprosy should be considered even in those unusual situations. ${ }^{[9]}$

Though leprosy is a rare cause of lymphadenopathy, but lymph node biopsy can surely reveal the diagnosis. In one study done in Pakistan in 2000 by Abdullah et al., lymph node biopsy done in 872 cases of lymphadenopathy. Major causes were tuberculosis, reactive hyperplasia, and lymphoma. However, $0.3 \%$ cases was diagnosed as leprosy. ${ }^{[10]}$

Fine needle aspiration cytology is also a useful aid to diagnose leprosy involvement of lymph nodes, but problems with this are getting inadequate specimen or necrotic material only or getting material from noncontributory areas. It also damages the tissue architecture and causes problem during histopathology. In one study done by Ahamad et al. which was published on 2009, they examined FNAC of 42 cases of lymph node involvement in leprosy. And 14 of the cases showed nonspecific features, which were later confirmed as leprosy by histopathology. $\cdot^{[11]}$

As in this case, if a clinician encounters lymphadenopathy in an elderly patient with no overt skin lesions or deformities, he is unlikely to suspect leprosy and also unlikely to perform a detailed neurological examination. Only a detailed history and examination can avoid misdiagnosis in such patients. Leprosy is a nonfatal and treatable condition; therefore, prompt initiation of appropriate medicines can prevent further complications.

This report highlights the importance of systemic involvement in leprosy, especially when the initial presentation is with lymphadenopathy. So clinicians practicing in endemic areas should bear this fact in mind.

\section{REFERENCES}

1. Gelber RH. Leprosy. In: Longo DL, Fauci AS, Kasper DL, Hauser SL, Jameson JL, Loscalzo J, editors. Harrison's Principles of Internal Medicine. $18^{\text {th }}$ ed. New York: McGraw Hill; 2011. p. 1359-65.

2. Park K. Park's Text Book of Preventive and Social Medicine. $20^{\text {th }}$ ed. Jabalpur: Banarsidas Bhanot Publishers; 2009. p. 778-90.

3. Kempf W, Hantschke M, Kutzner H, Burgdorf WH. Dermatopathology. Germany: Springer; 2008. p. 90-1.

4. Job CK. Pathology of leprosy. In: Hastings RS, Opromolla DV, editors Leprosy. $2^{\text {nd }}$ ed. Philadelphia: Churchill Livingstone; 1994. p. 190-233.

5. Gupta JC, Panda PK, Shrivastava KK, Singh S, Gupta DK. A histopathological study of lymphnodes in 43 cases of leprosy. Lepr India 1978;50:196-203.

6. Rosai J, editor. Lymph nodes. In: Rosai and Ackerman's Surgical Pathology. $10^{\text {th }}$ ed. St. Louis: CV Mosby; 2011. p. 1789-90.

7. Jopling $W H$, McDougall AC, editors. The disease. In: Handbook of Leprosy. $5^{\text {th }}$ ed. New Delhi: CBS Publishers; 2000. p. 10-49.

8. Kar HK, Mohanty HC, Mohanty GN, Nayak UP. Clinico-pathological study of lymph node involvement in leprosy. Lepr India 1983;55:725-38.

9. Nery JA, Schreuder PA, de Mattos PC, de Mendonça LV, Tardi RT, de Mello S, et al. Hansen's disease in a general hospital: Uncommon presentations and delay in diagnosis. J Eur Acad Dermatol Venereol 2009;23:150-6.

10. Abdullah P, Mubarik A, Zahir N. The importance of lymph node biopsy in diagnosis on lymphadenopathy. J Coll Physicians Surg Pak 2000;10:298-301.

11. Ahamad MS, Ahmed AS, Rahman AJ. Fine needle aspiration cytology of lymph node in leprosy. Bangladesh Med Res Counc Bull 2009;35:69-70.

How to cite this article: Chowdhury AR, Bandyopadhyay G, Bhattacharyya P, Chakraborty S. An unusual presentation of leprosy: Lepromatous lymphadenitis. Int J Med Public Health 2015;5:381-3.

Source of Support: Nil, Conflicts of Interest: None declared. 